\title{
Enhanced emotional reactivity after selective REM sleep deprivation in humans: an fMRI study
}

\section{Alejandra Rosales-Lagarde ${ }^{1}$, Jorge L. Armony ${ }^{2}$, Yolanda del Río-Portilla ${ }^{1}$, David Trejo-Martínez ${ }^{3}$, Ruben Conde $^{3}$ and Maria Corsi-Cabrera ${ }^{1 *}$}

${ }^{1}$ Faculty of Psychology, Laboratory of Sleep, Universidad Nacional Autónoma de México, México DF, México

${ }^{2}$ Department of Psychiatry, McGill University and Douglas Mental Health University Institute, Montreal, QC, Canada

${ }^{3}$ Module of Neuroimage and Cognition, Hospital Ángeles del Pedregal, Mexico City, Mexico

Edited by:

Carlos Tomaz, University of Brasilia,

Brazil

\section{Reviewed by:}

Irini Skaliora, Biomedical Research

Foundation of the Academy of

Athens, Greece

Akshay Anand, Post Graduate

Institute of Medical Education and

Research, India

\section{*Correspondence:}

María Corsi-Cabrera, Facultad de

Psicología Posgrado, Laboratorio de

Sueño, Universidad Nacional

Autónoma de México, Av.

Universidad 3004, DF 04510,

México.

e-mail:corsi@unam.mx
Converging evidence from animal and human studies suggest that rapid eye movement (REM) sleep modulates emotional processing. The aim of the present study was to explore the effects of selective REM sleep deprivation (REM-D) on emotional responses to threatening visual stimuli and their brain correlates using functional magnetic resonance imaging (fMRI). Twenty healthy subjects were randomly assigned to two groups: selective REM-D, by awakening them at each REM sleep onset, or non-rapid eye movement sleep interruptions (NREM-I) as control for potential non-specific effects of awakenings and lack of sleep. In a within-subject design, a visual emotional reactivity task was performed in the scanner before and $24 \mathrm{~h}$ after sleep manipulation. Behaviorally, emotional reactivity was enhanced relative to baseline (BL) in the REM deprived group only. In terms of $\mathrm{fMRI}$ signal, there was, as expected, an overall decrease in activity in the NREM-I group when subjects performed the task the second time, particularly in regions involved in emotional processing, such as occipital and temporal areas, as well as in the ventrolateral prefrontal cortex, involved in top-down emotion regulation. In contrast, activity in these areas remained the same level or even increased in the REM-D group, compared to their BL level. Taken together, these results suggest that lack of REM sleep in humans is associated with enhanced emotional reactivity, both at behavioral and neural levels, and thus highlight the specific role of REM sleep in regulating the neural substrates for emotional responsiveness.

Keywords: REM sleep deprivation, emotional reactivity, emotion, fMRI

\section{INTRODUCTION}

Several studies have recently investigated whether sleep plays a role in emotional regulation. These studies have shown a negative impact of total sleep deprivation (TSD) on mood and emotional processing (Dinges et al., 1997; Zohar et al., 2005; Franzen et al., 2008). For example, following TSD subjective responses to frustration and outward expressions of negative responses are augmented (Kahn-Green et al., 2006), emotional intelligence and coping skills are decreased (Killgore et al., 2008), the ability to make subtle discriminations of complex emotional blended face expressions is adversely affected (Huck et al., 2008), decisionmaking under uncertainty is compromised (Killgore et al., 2006; McKenna et al., 2007) and utilitarian judgments are favored (Killgore et al., 2007). Furthermore, sleep loss affects the neural systems associated with risky decisions (Venkatraman et al., 2007) and with successful recognition of emotional material (Sterpenich et al., 2007). In particular, larger and more extended amygdala activation during viewing increasingly negative stimuli has been found after TSD (Yoo et al., 2007). Taken together, these studies provide strong support to the notion that sleep is necessary for normal emotional functioning. However, as all these studies used TSD, they did not address the important question of whether all phases of sleep are critical for emotional processing or whether, for instance, non-rapid eye movement (NREM) and rapid eye movement (REM) sleep play different roles in emotion regulation.

Indeed, sleep neurobiology suggests that REM sleep may be particularly related to emotion. Emotional brain systems are selectively activated during this phase of sleep relative to wakefulness, including the amygdaloid complex, anterior cingulate, medial and orbital frontal cortices, and posterior association areas (Maquet et al., 1996; Braun et al., 1997). Magnetoencephalography current density is increased several milliseconds prior to REM sleep rapid eye movements in right amygdala and parahippocampal gyrus (Ioannides et al., 2004). Behaviorally, enhanced negative ratings (Wagner et al., 2002; Gujar et al., 2011) and memory for emotional stimuli following periods of sleep rich in REM (Wagner et al., 2001; Nishida et al., 2009) have been reported.

Studies in experimental animals have directly shown that REM sleep deprivation (REM-D) has a significant effect on emotion: shock-induced fighting is augmented (Morden et al., 1968) and fear is diminished (Hicks and Moore, 1979; Martínez-González et al., 2004). These findings suggest that REM sleep contributes to reestablish the adequate emotion-related neural excitability necessary on the following day for evaluation of potential danger and 
for controlling reactivity to emotional, particularly threat-related stimuli (Horne, 2000; Walker, 2009; Walker and van der Helm, 2009), and that when this is not achieved, emotional reactivity to such cues is enhanced.

Although several behavioral and neuroimaging studies have been carried out concerning the role of REM sleep in memory processes in humans (for review: Rauchs et al., 2005; Walker and Stickgold, 2006; Chuah and Chee, 2008), very few studies have directly investigated the role of selective REM-D on emotional regulation. Early studies found that, consistent with animal studies, subjects deprived of REM sleep showed irritability and anxiety (Dement and Fisher, 1963), deterioration in interpersonal relationships and increased signs of confusion and suspicion (Agnew et al., 1967), as well as poorer adaptation to stress-induced by viewing an emotionally arousing film (Greenberg et al., 1972). However, the consequences of REM-D on reactivity to threatrelated stimuli and, in particular, its cerebral correlates have not yet been investigated in humans.

Therefore, the aim of the present study was to explore the effect of selective REM-D on emotional reactivity to threatening visual stimuli and its brain correlates using functional magnetic resonance imaging (fMRI). Given that it has been proposed that REM sleep plays a role in reprocessing emotional information (Wagner et al., 2001, 2002; Nishida et al., 2009) and in stabilizing emotional system reactivity (Horne, 2000; Walker, 2009; Walker and van der Helm, 2009), a within-subject design was employed in which subjects were scanned twice, before and after one night of either selective REM-D or NREM sleep interruptions (NREM-I). In both tests, the same paradigm and stimuli was used in order to better allow for a direct comparison between conditions.

\section{MATERIALS AND METHODS SUBJECTS}

Twenty right-handed adult male volunteers between 21 and 35 years of age (average 24.2; SD 4.0) participated in the fMRI study after giving their written informed consent. They were recruited from the university community (mean education $=16.5$; $\mathrm{SD}=$ 1.4 years) and received financial compensation for their participation. Before the experiment, subjects completed a structured clinical interview and kept a sleep log of 15 days to check for the absence of sleep disturbances and to record their usual bedtime and sleep duration. Only volunteers with regular sleeping habits (average $7.38 \mathrm{~h} /$ night; SD 0.09), and regular bedtime hours (from 22:00-24:00 h to 06:00-08:00 h), with no symptoms associated with sleep disorders, no history of medical, psychiatric or neurological disorders, and free of drugs or medications were included in the study. All participants scored below the cutoff point for moderate depression on the Beck Depression Inventory (average 3.6; SD 3.2). All subjects had normal or corrected-to-normal vision. The protocol was approved by the Ethical Committee of the Faculty of Medicine of the National Autonomous University of Mexico.

Subjects were randomized into two groups: One group was selectively REM-sleep deprived $(n=12)$ and the other $(n=8)$ was submitted to the same number and distribution across the night of NREM-I to control for non-specific effects of sleep disruption and fragmentation. Due to excessive movement during scanning, data from one participant in the NREM-I group had to be discarded.

\section{SLEEP MANIPULATION}

All participants slept for four consecutive nights at the laboratory in a soundproof room with controlled temperature: the first for adaptation to recording procedures, the second as baseline (BL), the third for experimental treatment (EXP)—either REM-D or NREM-I-, and the fourth night to assess sleep recovery (REC). All participants were required to abstain from caffeine-containing beverages and alcohol, and to avoid napping 3 days before the adaptation night and throughout the experiment. After the REMD or NREM-I nights, subjects remained near the laboratory and were supervised continuously during all day to prevent naps. Breakfast, lunch, and dinner were provided.

Standard polysomnography (PSG), electroencephalography (EEG), electrooculogram (EOG), and electromyogram (EMG) were recorded during $\mathrm{BL}$, experimental and recovery nights. Electrical activity was recorded using a Grass 8-20 E polygraph with filters set at 1 and $70 \mathrm{~Hz}$ for EEG, at 10 and 70 for EMG and at 0.3 and 15 for EOG. Sleep stages were identified according to standard procedures using $30 \mathrm{~s}$ epochs (Rechtschaffen and Kales, 1968). Sleep stage percentages were calculated over total sleep time (time from sleep onset to morning awakening after the time awake during the night is subtracted), and wakefulness after sleep onset (WASO) was calculated from sleep onset to morning awakening over total sleep time plus wakefulness. The latter included spontaneous awakening during the BL and REC nights, and both spontaneous and experimentally induced awakenings during the EXP night.

Subjects in the selective REM sleep deprived group were awakened every time that the PSG showed that slow wave activity, sleep spindles and $\mathrm{K}$ complexes, were no longer present in the EEG which, instead, was characterized by low voltage fast activity accompanied by decreased EMG activity for $60 \mathrm{~s}$ with or without REMs (Rosales-Lagarde et al., 2009). Participants were awakened by the experimenter entering the recording chamber with lightsoff and by increasing the volume of a previously recording tape with the name of the subject until the subject was fully awake. They were kept awake during $2 \mathrm{~min}$ by asking them incidental questions (e.g., name the days of the week), to avoid the immediate relapse into REM sleep (Endo et al., 1998). The subjects of the NREM-I group were awakened in the same manner but from stages 2, 3, or 4 of NREM sleep.

Sleep variables were compared by Two-Way mixed ANOVAs (groups $x$ nights) with the two groups as the between-subject factor and the three PSG nights (BL, EXP, and REC) as the withinsubject factor. Significant interactions were further tested with Tukey studentized $t$-tests.

\section{EXPERIMENTAL TASK}

All participants performed the Emotional Reactivity Task in the MR scanner in two separate sessions, once in the evening after BL night and again in the evening after either REM-D or NREM-I. The same stimuli were used in both sessions. To avoid confounding circadian effects, scanning sessions took place at the same time of day around $6 \mathrm{pm}$ (between 5 and $7 \mathrm{pm}$ ). Additionally, as a 


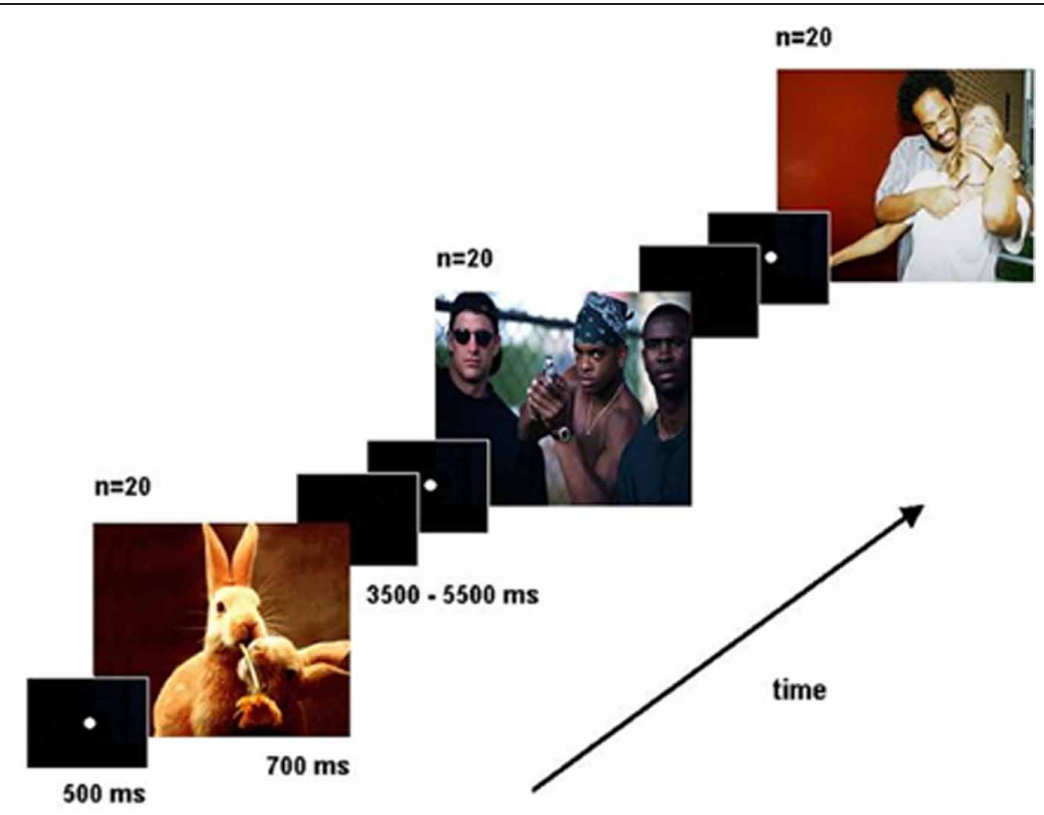

FIGURE 1 | Schematic of the Emotional Reactivity Task.

control for unspecific effects of sleep interruption on attention, all subjects also performed outside the scanner a visual sustained attention task (VISAT) that has been previously employed to assess sleep deprivation effects (Corsi-Cabrera et al., 1996).

The emotional reactivity task (Figure 1) involved the presentation of 60 pictures from the International Affective Pictures System (Lang et al., 2005). Subjects were instructed to imagine themselves as part of the scene and react to the situation as soon as possible either by defending themselves (i.e., firing a bullet) or not, by pressing one of two buttons with the right index or middle finger (counterbalanced across sessions and subjects). Thus, a specific response was required for every slide in order to control for motor response activations. Pictures were selected according to the normative valence ratings and were classified into two extreme valence categories, 40 negative valence pictures (20 directly threatening the observer and 20 threatening a third party, mean valence $=3.46$ ), and 20 non-menacing positive pictures (mean valence $=7.19$ ). Trials were assigned a posteriori to one of two categories based on each subject's response: those eliciting a defense response were labeled as high emotional reactivity trials (HER) and non-defending responses as low emotional reactivity trials (LER). All pictures were shown in a randomized order. Each picture was presented for $700 \mathrm{~ms}$ preceded by a fixation point $(500 \mathrm{~ms})$ at the center of the screen and followed by a black screen. The duration of the inter-trial black screen varied randomly between 3.5 and $5.5 \mathrm{~s}$.

The number of HER and LER responses and reaction times were computed and analyzed using single and independent $t$-tests.

\section{IMAGING PROCEDURE AND ANALYSIS}

Functional MRI data was acquired with a General Electric 1.5 Tesla MR system at the Hospital Angeles del Pedregal. For each subject and each session, 120 echo-planar image volumes were acquired $(86 \mathrm{~mm}$-thick axial slices with the third one positioned parallel to the anterior-posterior commissure; $\mathrm{TR}=3 \mathrm{~s}$; TE $=$ $27 \mathrm{~ms}$; interslice gap: $4 \mathrm{~mm}$; field of view: $24 \times 24 \mathrm{~cm}$, matrix: $128 \times 128$ ), in two runs of 60 scans with three dummy scans discarded before analysis due to T1 saturation effects. Before the functional runs, a T1-weighted anatomical scan was obtained (TR $=18.4 \mathrm{~ms}, \mathrm{TE}=4.2 \mathrm{~ms}, 0.47 \times 0.47 \times 3 \mathrm{~mm}^{3}$ voxel size).

Functional data was preprocessed following standard procedures using SPM2 (www.fil.ion.ucl.ac.uk/spm/software/spm2). Briefly, functional images for each subject were realigned to the first image of each session to correct for head movement between scans and corrected for differences in slice acquisition times. Images were then spatially normalized to the Montreal Neurological Institute (MNI) space (Evans et al., 1994) and spatially smoothed using an isotropic Gaussian kernel of $8 \mathrm{~mm}$ Full width at half maximum (FWHM).

Events were modeled as pseudo-delta functions coinciding with stimulus onset, convolved with the synthetic hemodynamic response function. Stimuli were divided into high- and lowemotional reactivity based on each subject's response, as indicated above.

Brain responses associated with each experimental condition were estimated according to the general lineal model for an eventrelated design at each voxel. In order to identify the brain regions associated with the performance of the Emotional Reactivity Task, we first analyzed cerebral activity under BL sleep conditions (i.e., prior to sleep deprivation/interruption). To characterize the effects of the sleep manipulation on the Emotional Reactivity Task, contrasts were obtained comparing BL and REM deprivation nights (PRE-REM-D minus POST-REM-D), or BL and NREM interruption nights (PRE-NREM-I minus POST-NREM-I). These contrasts were computed for task related 
activations (HER + LER) and for emotional reactivity (HER LER). Statistical maps were thresholded at $p<0.001$ (uncorrected for multiple comparisons), with a minimum cluster size of 10 voxels. In addition, parameter estimates for the activation peaks obtained in the contrasts of interest were extracted for plotting and to conduct further post-hoc $t$-tests. To further confirm that the differences in activation before and after sleep manipulation were indeed related to REM sleep, we performed regression analyses between the contrasts of interest and percentage of REM sleep for all 19 subjects.

\section{RESULTS}

\section{SLEEP}

There were no significant differences between groups in the mean number of hours of sleep in the 2 weeks prior to the study, as recorded from the subjects' sleep diaries $(\mathrm{REM}-\mathrm{D}=7.26, \mathrm{SD} 0.87$; NREM-I $=7.48$, SD $1.05 ; t=0.39, p=0.7$ ).

As shown in Figure 2, REM-D procedure successfully reduced REM sleep in the REM-D group only. Statistical results for ANOVAs are shown in Table 1. REM sleep percentage differed significantly between groups and nights. Post-hoc comparisons
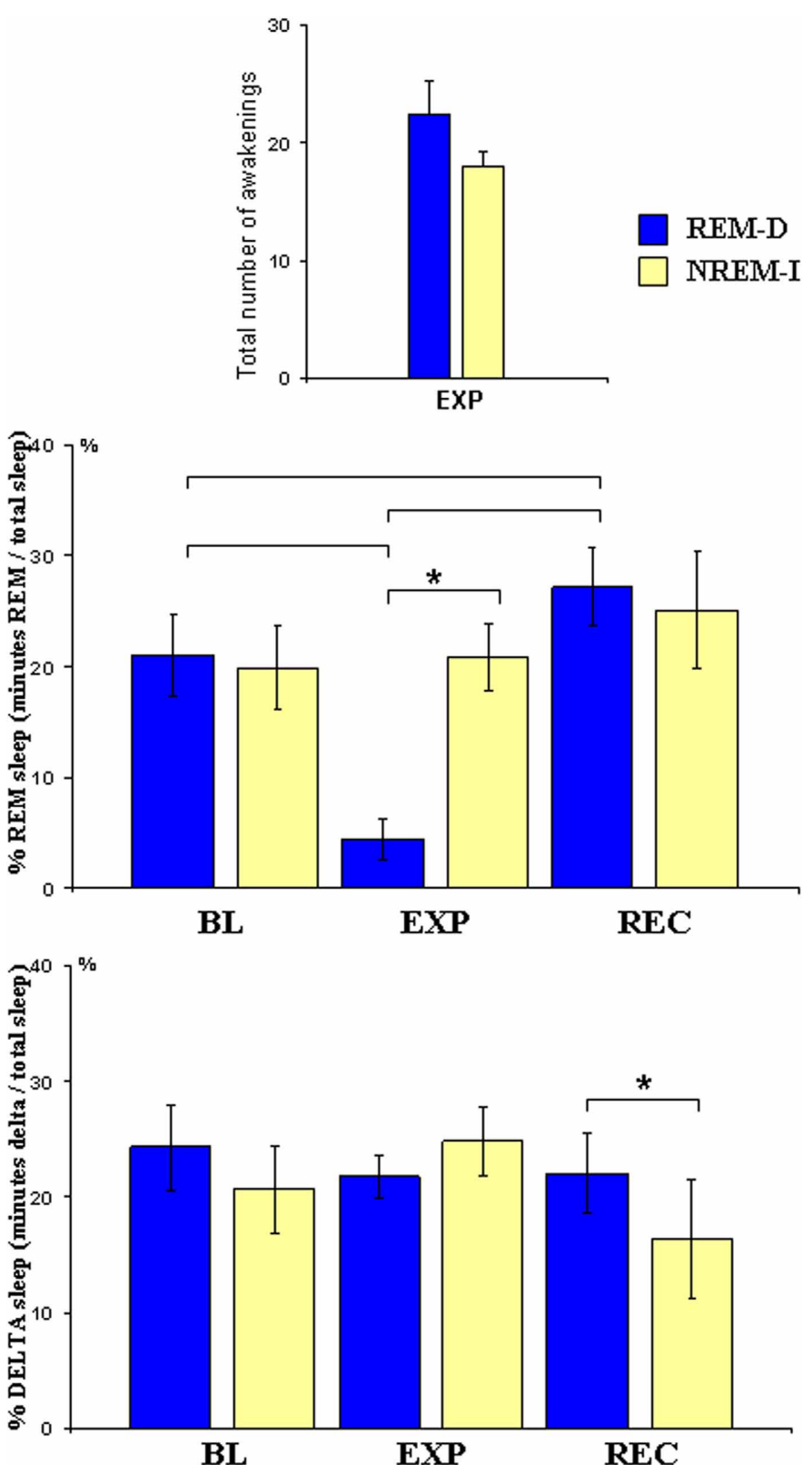

FIGURE 2 | Mean and standard error of total number of experimental awakenings during sleep manipulation night, and of percentage of REM sleep (minutes of REM/minutes total sleep) and delta sleep (minutes of stage $3+4 / \mathrm{min}$ total sleep) at baseline (BL), experimental (EXP) and recovery (REC) nights for the REM sleep deprivation (REM-D), and non-REM sleep interruptions (NREM-I) groups; Brackets indicate significant post-hoc differences in the REM-D group whereas asterisk above bracket represents differences between groups. 
Table 1 | Polysomnographic sleep measures.

\begin{tabular}{|c|c|c|c|c|c|c|c|c|c|}
\hline & \multicolumn{3}{|c|}{ REM-D group } & \multicolumn{3}{|c|}{ NREM-I group } & \multicolumn{3}{|c|}{ Mixed ANOVA } \\
\hline TST (min) & $446.3(38.0)$ & $350.3(47.0)$ & $447.2(49.6)$ & $473.9(55.4)$ & $426.2(44.1)$ & $479.6(57.4)$ & $0.02(6.07)$ & $0.0001(26.43)$ & n.s. \\
\hline Stage $1 /$ TST & $3.4(1.6)$ & $10.5(4.5)$ & $3.0(1.2)$ & $2.6(1.8)$ & $4.0(1.6)$ & $4.8(3.2)$ & $0.03(5.15)$ & 0.0001 (13.59) & $0.0002(12.15)$ \\
\hline Delta sleep/TST & $24.3(6.8)$ & $23.5(6.0)$ & $22.1(4.6)$ & $20.7(5.0)$ & $24.9(5.2)$ & $16.4(3.0)$ & n.s. & $0.01(4.83)$ & n.s. \\
\hline REM sleep/TST & $21.01(3.7)$ & $4.03(1.3)$ & $27.2(3.5)$ & $19.8(3.8)$ & $20.8(2.9)$ & $25.1(5.2)$ & $0.001(15.66)$ & $0.0000(89.29)$ & $0.0001(53.56)$ \\
\hline WASO/TST & $2.8(2.8)$ & $19.7(14.1)$ & $3.5(4.9)$ & $2.2(1.8)$ & $14.0(5.2)$ & $2.9(3.7)$ & n.s. & $0.0001(29.20)$ & n.s. \\
\hline Latency to REM (min) & $112.1(31.9)$ & 96.7 (37.7) & $96.8(35.1)$ & $81.9(16.7)$ & $102.6(24.3)$ & $79.9(19.7)$ & n.s. & n.s. & n.s. \\
\hline
\end{tabular}

REM-D, Rapid Eye Movement Sleep Deprivation; NREM-I, Non Rapid Eye Movement Sleep Interruptions; BL, base line night; REC, recovery night; TST, total sleep

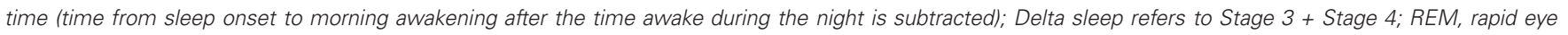
movement sleep; WASO, wakefulness after sleep onset to morning awakening (TST plus wakefulness); $p<0.05$.

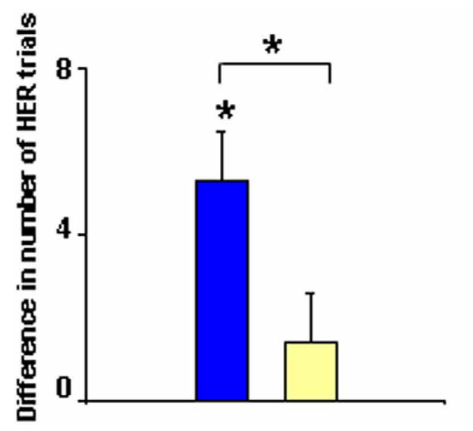

FIGURE 3 | Difference in the number of high emotional reactivity trials (HER, see Methods for details) and in reaction times for HER and low emotional reactivity trials (LER) after REM sleep deprivation (REM-D) or

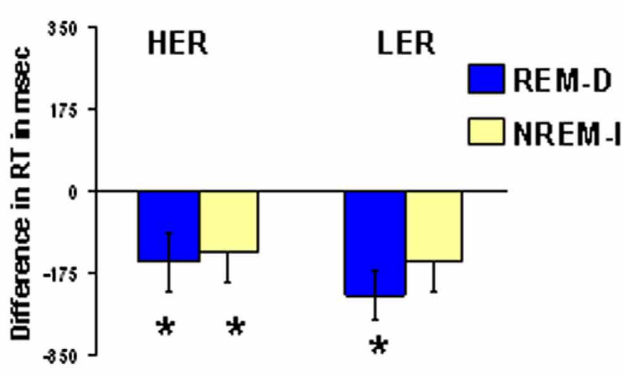

non-REM sleep interruptions nights (NREM-I). Asterisks above brackets indicate significant post-hoc differences between groups whereas asterisks above individual bars represent significant differences from zero. showed that REM sleep percentage was significantly reduced from $21.01 \%$ over total sleep time in BL night to $4.03 \%$ during the REM deprivation night $(p<0.01)$, followed by a significant, though small, REM rebound in the recovery night $(p<0.01)$. In contrast, there were no differences in the amount of REM sleep among nights in the NREM-I group. Group-by-night interactions were also significant for Stages 1 and 2. Both sleep stages were higher for the REM-D during the experimental night. Importantly, the average number of sleep interruptions did not differ significantly between groups (Figure 2). The difference in standard deviation between groups was due to two subjects in the REM-D group with large number of interruptions (37 and 45). Removing these two subjects from the analyses did not substantially change the results.

Night effects were also significant for delta sleep (Figure 2); post-hoc comparisons showed that these effects were due to lower delta sleep in the recovery night $(p<0.05)$ but not during the experimental night. In addition, as it could be expected from experimental awakenings, WASO increased in both groups during the experimental night as compared to $\mathrm{BL}(p<0.01)$ and recovery nights $(p<0.01)$, with no group differences observed.
Importantly, overall sleep architecture was not modified in the NREM-I group during the experimental night and therefore this group can be used as a control group for non-specific effects due to sleep interruptions.

\section{BEHAVIORAL RESULTS}

Emotional reactivity task

As shown in Figure 3, the number of HER responses was increased after REM-D (before REM-D: mean $=26.3, \mathrm{SD}=4.8$; after REM-D: mean $=31.6, \mathrm{SD}=4.7 ; t=4.50 ; p<0.0009$ ), whereas emotional reactivity was not modified in the NREM-I group (before NREM-I: mean $=30.3, \mathrm{SD}=7.8$; after NREM-I: mean $=31.7, \mathrm{SD}=2.9 ; t=1.24 ; p=0.26$ ).

Reaction times decreased significantly from the first to the second time that the task was performed for HER responses in the two groups (REM-D: $t=2.40 ; p<0.03$; NREM-I: $t=$ $2.43 ; p<0.05$ ), with no significant group differences. Reaction times also decreased the second time for LER responses in the REM-D group, while the difference in the NREM-I group failed to reach the standard level of significance $(t=2.20$; $p=0.06)$. 


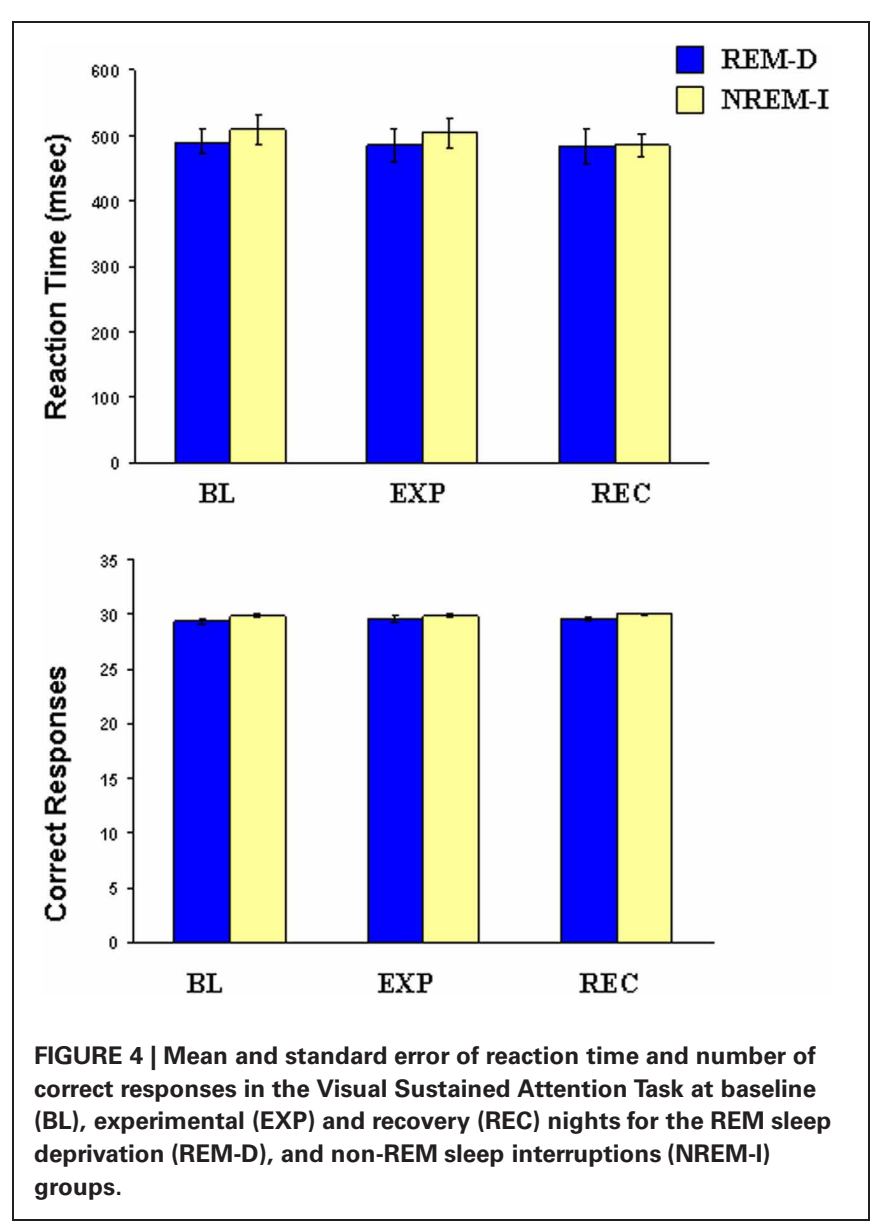

\section{Visual sustained attention task}

Reaction time and correct responses (Figure 4) were not significantly different in any of the two groups between sessions (reaction time: group main effect $\left[F_{(1,17)}=0.38 ; p=0.55\right]$, nights main effect $\left[F_{(2,34)}=0.24 ; p=0.63\right]$, group-bynight $\left[F_{(2,34)}=0.01 ; p=0.94\right] ;$ correct responses: group main effect $\left[F_{(1,17)}=1.64 ; p=0.21\right]$, night main effect $\left[F_{(2,34)}=0.11 ; \quad p=0.74\right], \quad$ group-by-night $\left[F_{(2,34)}=0.11\right.$; $p=0.74])$.

\section{FUNCTIONAL MRI RESULTS \\ Baseline}

Table 2 shows the significant activations for the main effect of the Emotional Reactivity Task (HER + LER) after BL sleep (i.e., before sleep manipulation) in the 19 subjects. This contrast revealed large activations of right superior (BA9), middle (BA6) and inferior (BA46/9; BA45) frontal gyri, insula (BA47), (BA32/8/6), precentral cortex (BA4), inferior parietal lobule (BA2/3/40) and precuneus (BA7), and in middle and inferior frontal gyri (BA9/9/6; BA44/45/46), medial frontal gyrus (BA10), fusiform gyrus (BA19/18) and caudate tale of the left hemisphere.

The contrast of HER minus LER trials showed that high emotional responses resulted in significant increased activation in the right inferior frontal gyrus (BA45/47), while no significant activations associated with the opposite contrast (LER - HER) were observed.

\section{Effects of sleep manipulation}

Activation associated with task performance [(HER + LER $)$ vs. fixation] decreased after NREM-I in comparison to post BL-sleep session (Figure 5A), as it could be expected for a second exposure to the same stimuli (Table 3). Significant decreased activations were seen in right inferior and middle frontal gyri (BA45; BA46 and BA11) and right fusiform gyrus (BA20), as well as in left superior frontal gyrus (BA11), inferior parietal lobule (BA40), posterior middle temporal gyrus (BA21) and parahippocampal gyrus.

In contrast, very little difference was observed when comparing the first and second sessions in the REM-D group. Significant deactivations associated with the Emotional Reactivity Task performance after REM-D, as compared to post BL-sleep (Table 3 and Figure 5B), were only found in left anterior (BA32) and posterior cingulate gyrus (BA30 and BA31). Furthermore, post-hoc analyses of the parameters estimates for peak voxels of decreased activation in the NREM-I group revealed no significant effects for the REM-D group ( $p$ 's $>0.05$ ), except for the left posterior middle temporal gyrus (BA21) where it also decreased significantly $(p=0.02)$ in the REM-D group (Figure 5A).

The reverse comparison revealed that only the left thalamus showed increased activation in the NREM-I group as a function of sleep manipulation, compared to $\mathrm{BL}$, without any change in the REM-D group for this region.

In terms of emotional responses, comparison of the highand low-emotional reactivity trials (HER > LER) before and after sleep manipulation showed that HER trials elicited increased activation in the left middle occipital gyrus (BA19/18) following REM-D. As shown in Figure 6 and Table 3, post-hoc analyses of the parameters estimates revealed that, in contrast, activity in this region decreased significantly after NREM-I. The reverse contrast did not show significant differences. The contrast between HER and LER trials in the NREM-I group did not differ significantly from BL session.

\section{Regression analysis}

Significant activations obtained in the correlations between brain activity and percentages of REM sleep for all subjects are shown in Table 4.

For the contrast of task vs. BL, we observed a negative correlation in left middle temporal gyrus (BA21) in the same region that was deactivated in the NREM-I group, as well as in the cerebellum bilaterally; whereas REM sleep percentage correlated positively with activation in the right putamen. For the HER > LER, a negative correlation was found with REM sleep percentage bilaterally in the cingulate gyrus (BA23), lingual gyrus (BA17/18) and fusiform gyrus (BA18 and extending to BA19 in the left hemisphere), in right precuneus and superior parietal lobule (BA7) and in left inferior frontal gyrus (BA9) and left cerebellum. Interestingly, the activations in visual areas were similar to those found to be more active after sleep manipulation in the REM-D group. 
Table 2 | Activations during the emotional reactivity task after baseline sleep.

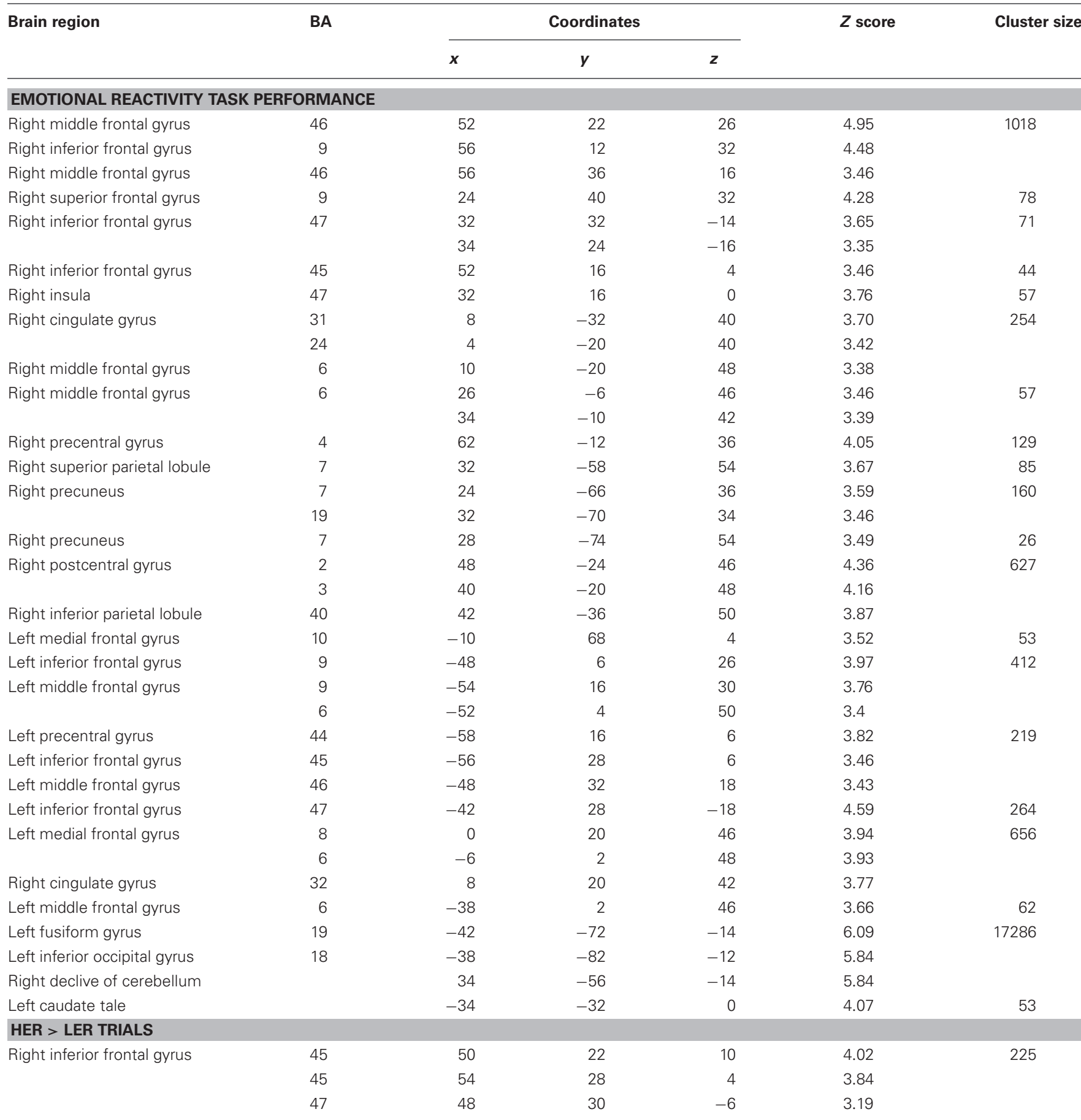

All of the regions presented are significant at $p<0.001$ (uncorrected).

BA, Brodmann area; HER, high emotional reactivity trials; LER, low emotional reactivity trials (see Materials and Methods for details).

\section{DISCUSSION}

In the present study we examined the impact of selective REM-D on emotional reactivity to threatening visual stimuli and the associated brain activity changes. The main findings are that emotional reactivity, as assessed by defensive responses (HER trials), was enhanced after one night of near-total REM-D, while reactivity did not change after an equal number of NREM-I. Neural systems associated with task performance were differently affected by REM-D than by NREM-I.

Importantly, the observed effects are likely to be specifically due to REM-D, given that the procedure successfully reduced REM sleep to only $4 \%$ over total sleep time in the REM-D 

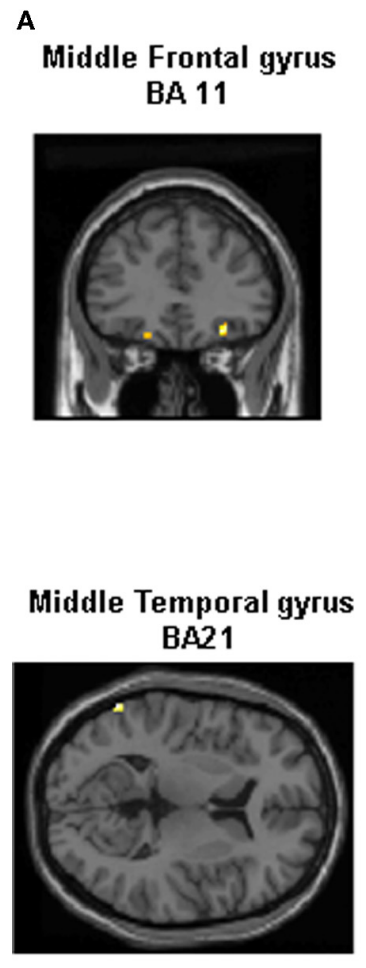
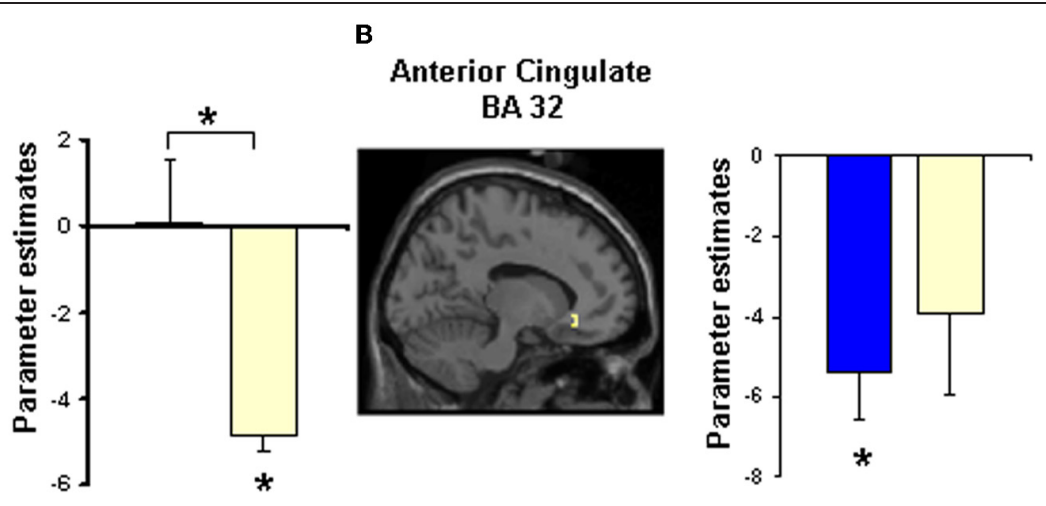

REM-D

NREM-I

Posterior Cingulate BA. 30
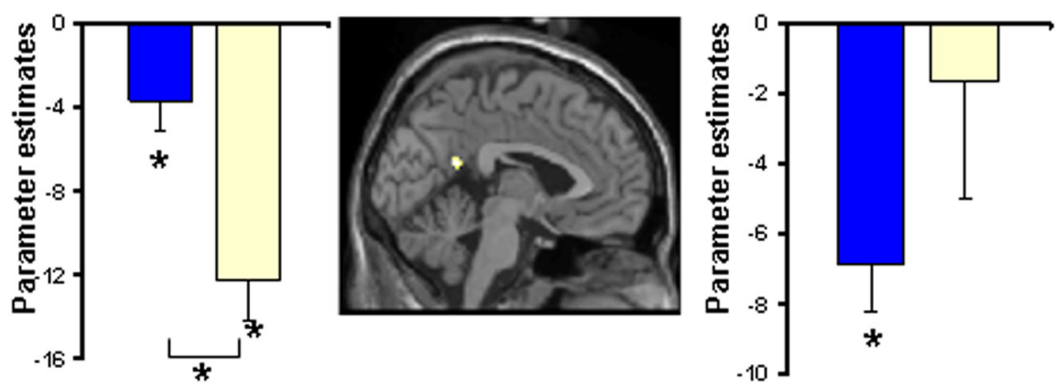

FIGURE 5 | Statistical maps for some of the regions showing significant differences in activation during performance of the Emotional Reactivity Task (high + low emotional reactivity trials) after (A) non-REM sleep interruptions (NREM-I) and (B) REM sleep deprivation (REM-D), relative to baseline sleep. Maps are thresholded at $p<0.001$ (uncorrected). See Table $\mathbf{3}$ for all significant activations. Bar graphs

deprivation night without altering delta sleep during the experimental night. Furthermore, the enhanced emotional reactivity after REM-D cannot be attributed to non-specific effects on attention, given that the VISAT did not differ in any of the two groups after sleep manipulation.

The Emotional Reactivity Task under BL sleep conditions activated areas that have been previously shown to be implicated in emotional response selection (Mitchell, 2011), including prefrontal regions and temporal areas. Critically, all of these cortical regions, except for the cingulate gyrus, decreased their activation after NREM-I, as it could be expected for a second exposure to the same task. Although the aim of the study was not to directly test memory, the Emotional Reactivity Task was performed twice, before and after sleep manipulation, and thus it is likely that the observed faster reaction times and decreased brain activation the second time that the task was performed were due to memory and/or practice effects (Chein and Schneider, 2005).

In stark contrast, in subjects who underwent selective and near-total REM-D activation remained at the same level the second time they performed the task, only significantly decreasing along the cingulate gyrus. In particular, the ventrolateral prefrontal cortex (BA45 and 47), involved in top-down emotional regulation (Mitchell, 2011), was reactivated in HER compared show the corresponding differences in activation between baseline and experimental night for the REM sleep deprivation and non-REM sleep interruption groups. Coordinates are in MNI space. Asterisks above brackets indicate significant post-hoc differences between groups whereas asterisks above individual bars represent significant differences from zero $(p<0.05)$. to LER trials at the same level as the first time they performed the task in the REM-D subjects, whereas activity in this region decreased in the NREM-I group. These results indicate that the same level of brain activation was required for appropriately performing the task a second time in the absence of REM sleep, suggesting that with insufficient REM sleep, performing the task a second time still required some degree of supervisory control from the ventrolateral prefrontal cortex, a region involved in topdown emotional regulation (Mitchell, 2011). These results could be interpreted as suggesting either a compensatory process necessary to cope with response selection, similar to what has been shown for cognitive tasks after TSD (Drummond et al., 2006), or that the lack of sufficient REM sleep impairs the reorganization and flow of information to other brain regions as it has been shown for memory processes (Buzsáki, 1989; Fischer et al., 2005). after REM-D, relative to their own BL sleep, in left occipital association regions commonly activated when assigning meaning to visual emotional stimuli and in processes evaluating the affective valence of sensory events (Vuilleumier et al., 2001). In addition, increased bilateral activation in occipital and temporal visual areas showed a significant negative correlation with percentage of REM sleep in all subjects. The occipital cortex

Increased activation for HER compared to LER trials was seen 
Table 3 | Activations during the emotional reactivity task after sleep manipulation.

\begin{tabular}{|c|c|c|c|c|c|c|c|c|c|c|c|}
\hline \multirow[t]{2}{*}{ Brain region } & \multirow[t]{2}{*}{ BA } & \multicolumn{3}{|c|}{ Coordinates } & \multirow[t]{2}{*}{$Z$ Score } & \multicolumn{2}{|c|}{$\begin{array}{c}\text { REM-D } \\
\text { Paired } t \text {-test }\end{array}$} & \multicolumn{2}{|c|}{$\begin{array}{c}\text { NREM-I } \\
\text { Paired } t \text {-test }\end{array}$} & \multicolumn{2}{|c|}{$\begin{array}{c}\text { Independent } \\
\text { t-test }\end{array}$} \\
\hline & & $\boldsymbol{x}$ & $y$ & $z$ & & $\boldsymbol{t}$ & $p$ & $t$ & $\boldsymbol{p}$ & $\boldsymbol{t}$ & $\boldsymbol{p}$ \\
\hline \multicolumn{12}{|c|}{ EMOTIONAL REACTIVITY TASK PERFORMANCE (HER + LER) } \\
\hline \multicolumn{12}{|l|}{ NREM-I Group } \\
\hline Right inferior frontal gyrus & 45 & 54 & 26 & 22 & 4.25 & 0.91 & 0.37 & 13.41 & 0.0001 & 0.89 & 0.38 \\
\hline Right middle frontal gyrus & 46 & 46 & 22 & 20 & 3.88 & & & & & & \\
\hline Right middle frontal gyrus & 11 & 28 & 34 & -16 & 4.15 & 0.05 & 0.95 & 12.81 & 0.0001 & 2.48 & 0.02 \\
\hline Right fusiform gyrus & 20 & 42 & -36 & -14 & 3.78 & 0.87 & 0.40 & 9.81 & 0.0001 & 1.29 & 0.21 \\
\hline Left superior frontal gyrus & 11 & -24 & 40 & -22 & 3.93 & 0.63 & 0.53 & 9.15 & 0.0001 & 1.32 & 0.20 \\
\hline Left inferior parietal lobule & 40 & -40 & -54 & 38 & 4.02 & 0.44 & 0.66 & 14.75 & 0.0001 & 0.55 & 0.58 \\
\hline Left middle temporal gyrus & 21 & -62 & -58 & 8 & 3.56 & 2.53 & 0.02 & 6.39 & 0.0006 & 3.51 & 0.002 \\
\hline Left parahippocampal gyrus & & -32 & -20 & -12 & 3.26 & 0.21 & 0.83 & 7.77 & 0.0002 & 1.87 & 0.07 \\
\hline Left thalamus & & -10 & -16 & 10 & 3.56 & 0.009 & 0.99 & 9.81 & 0.0001 & 1.57 & 0.13 \\
\hline \multicolumn{12}{|l|}{ REM-D Group } \\
\hline Anterior cingulate gyrus & 32 & -12 & 30 & -10 & 3.38 & 4.61 & 0.0007 & 1.97 & 0.09 & 0.68 & 0.50 \\
\hline Posterior cingulate gyrus & 30 & -2 & -50 & 20 & 3.64 & 5.13 & 0.003 & 0.50 & 0.63 & 1.70 & 0.10 \\
\hline Cingulate gyrus & 31 & -24 & -38 & 38 & 3.58 & 4.74 & 0.0006 & 1.31 & 0.23 & 0.03 & 0.97 \\
\hline \multicolumn{12}{|c|}{ HIGH VS. LOW REACTIVITY TRIALS (HER > LER) } \\
\hline \multicolumn{12}{|l|}{ REM-D Group } \\
\hline \multirow[t]{3}{*}{ Middle occipital gyrus } & 19 & -30 & -88 & 8 & 3.71 & 5.40 & 0.0002 & 0.28 & 1.17 & 3.79 & 0.001 \\
\hline & 18 & -18 & -102 & 8 & 3.65 & & & & & & \\
\hline & 18 & -26 & -96 & 8 & 3.43 & & & & & & \\
\hline
\end{tabular}

All of the regions presented are significant at $p<0.001$ (uncorrected).

BA, Brodmann Area; REM-D, REM sleep deprived group; NREM-I, NREM sleep interruptions group, HER, high emotional reactivity trials; LER, low emotional reactivity trials.

\section{Middle Occipital gyrus}

BA 19
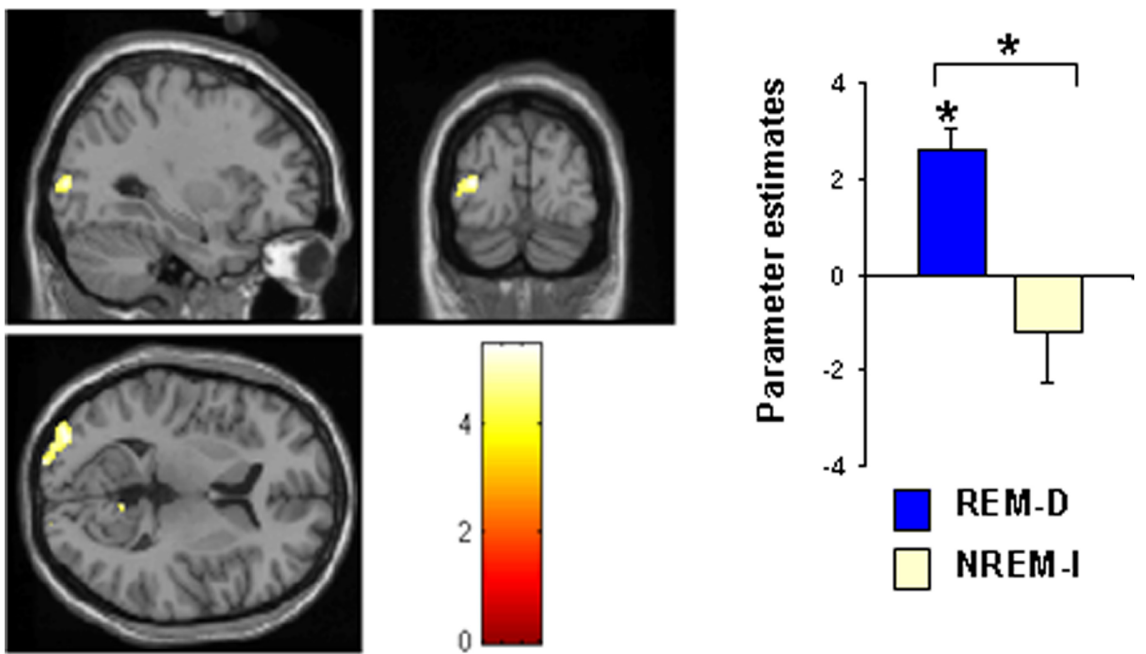

REM-D

NREM -I

FIGURE 6 | Statistical map showing the significant activation cluster $(-30-888)$ for the contrast high reactivity trials (HER) minus low reactivity trials (LER) after REM sleep deprivation (REM-D). The map is thresholded at $p<0.001$ (uncorrected). See Table 3 for all significant activations. Bar graphs show the corresponding differences in activation between baseline and experimental night for the REM sleep deprivation and non-REM sleep interruption groups. Asterisks above bars and brackets indicate significant difference from zero and between groups, respectively ( $p<0.05)$. 
Table 4 | Result from the correlation analysis with percentage REM sleep.

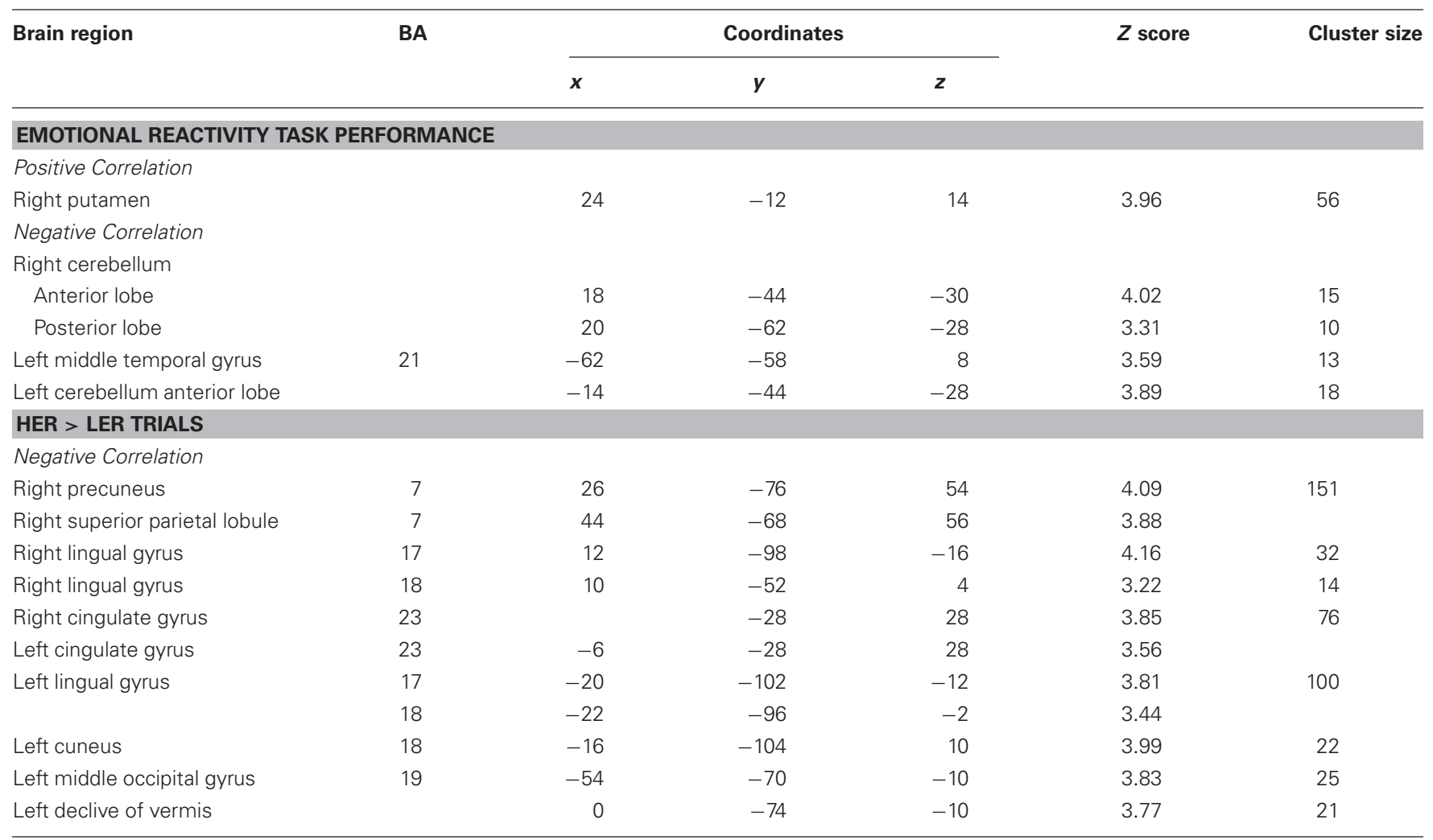

All of the regions presented are significant at $p<0.001$ (uncorrected).

BA, Brodmann area; HER, high emotional reactivity trials; LER, low emotional reactivity trials (see Materials and Methods for details).

is one of the brain regions more strongly activated by PontoGeniculate-Occipital waves (PGO) during REM sleep in cats. PGO waves reach their highest amplitude in the lateral geniculate body, primary and visual association areas in cats (Datta, 1997). Although PGO waves cannot be recorded in humans, PGO-like field potentials have been recorded in humans (Lim et al., 2007), and increased activity in both lateral geniculate body and occipital cortex has been reported with Positron Emission Tomography (PET) in humans (Hong et al., 1995; Peigneux et al., 2001). It has been shown that REM-D in rats increases the activity of Na-K ATPase enzyme (Gulyani and Mallick, 1993), leading to increased excitability of neurons (Das and Mallick, 2008). The usual inhibitory period observed after repetitive auditory stimulation is shortened after REM-D in evoked potentials (Dewson et al., 1967) and in pontine neurons (Mallick et al., 1991) in cats suggesting maintained excitability to the same stimulation. The increased activation in visual areas in the REM-D suggests that the lack of incoming phasic, PGO-like, activation in the REM-D group might facilitate visual cortex excitability in response to visual stimuli.

The present findings extend previous results showing that sleep plays a crucial role in emotional regulation (Dinges et al., 1997; Zohar et al., 2005; Kahn-Green et al., 2006; Killgore et al., 2006, 2007, 2008; McKenna et al., 2007; Franzen et al., 2008) and are consistent with studies showing modification of brain networks involved in emotional processing after TSD (Sterpenich et al., 2007; Venkatraman et al., 2007; Yoo et al., 2007). Present results highlight the crucial role of REM sleep in emotion, in line with the proposed role for REM sleep for stabilizing emotional system reactivity (Horne, 2000; Lara-Carrasco et al., 2009; Walker, 2009; Walker and van der Helm, 2009; Gujar et al., 2011). In addition, our findings are in line with animal studies showing enhanced reactivity to emotional stimuli after REM-D (Morden et al., 1968; Hicks and Moore, 1979; Martínez-González et al., 2004).

Several studies suggest a role of sleep in general (Wagner et al., 2001; Hu et al., 2006; Sterpenich et al., 2007; Payne et al., 2008; Gujar et al., 2011), and REM sleep in particular, in facilitating memory for emotionally salient stimuli in humans (Wagner et al., 2001; Nishida et al., 2009). Present results may seem incompatible with previous reports suggesting that REM sleep enhances aversive reactivity to (Wagner et al., 2002), and memory for, emotional, particularly negative, stimuli (Wagner et al., 2001; Nishida et al., 2009). However, several key methodological differences between our and these previous studies should be considered. First, Wagner et al. (2002) assessed emotional reactivity by subjective evaluation, which may not be directly comparable to the motor defensive response used here. Second, in previous studies REM sleep was not directly manipulated, but, rather, it was shown that the amount of natural REM sleep, either during the second half of the night (Wagner et al., 2001) or in naps (Nishida et al., 2009) was associated with memory enhancement. Finally, in 
the present study we did not directly test retention of emotional material but instead assessed reactivity by exposure to the same stimuli for a second time, which leaves open the possibility of poorer memory retention by lack of REM sleep. However, we do not believe that this is the case because although reaction times decreased in both groups for HER responses, as it could be expected for a second exposure to the same stimuli, BOLD signal increased or remained the same after REM-D instead of decreasing. The present results are consistent with the model proposed by Walker and van der Helm (2009) proposing that REM sleep might facilitate episodic memory and at the same time depotentiate the emotional tone or affective charge of the stimuli.

Taken together, these findings could be tentatively interpreted as suggesting that REM sleep is involved not only in memory enhancement but also in preparing the brain for the next day's demands, as it proposed by Walker (2009), by reprocessing information related to emotional experiences in a safe environment provided by atonia and free from high order control (Maquet et al., 1996; Corsi-Cabrera et al., 2003), and by modulating brain excitability (Das and Mallick, 2008) in a similar way as it has been proposed for sleep in general (Tononi and Cirelli, 2003). The activation of emotional systems during REM sleep may facilitate dissipation of accumulated excitability reestablishing an adequate level of emotional responsiveness for the next period of wakefulness (Corsi-Cabrera, 1983; Walker and van der Helm, 2009). In this case, the lack of REM sleep may affect the fine-tuning of networks involved in emotional reactivity by enhancing excitability and/or impairing assimilation of previous experiences, leading to hyper-reactivity and increased appraisal of potential danger.

\section{LIMITATIONS}

The goal of the present study was to investigate the specific effects of REM-D on emotional reactivity. Therefore, our results do not rule out the possibility that other sleep stages may also contribute to normal emotional functioning.

Present findings should be taken as preliminary given the small number of subjects tested. However, the use of a within-subject design allowed for a larger statistical power than that which would have resulted from a cross-sectional comparison. Furthermore, regression analyses performed with all 19 subjects largely confirmed the results obtained in the group-based (categorical) analyses. In order to avoid increased between-subject variability due to sex differences in emotional processing (Stevens and Hamann, 2012), our sample was restricted to male participants. Future studies should be conducted in women to determine to what extent the present results generalize to the entire population.

\section{REFERENCES}

Agnew, H. W., Webb, W. B., and Williams, R. L. (1967). Comparison of stage IV and REM sleep deprivation. Percept. Mot. Skills 24, 263-266.

Braun, A. R., Balkin, T. J., Wesensten, N. J., Carson, R. E., Varga, M., Baldwin, P., Selbie, S., Belenky, G., and Herscovitch, P. (1997). Regional cerebral blood flow Brain 120, 1173-1197.

Another potential limitation of the present study is the small number of slices acquired during fMRI scanning, due to technical reasons, reducing the spatial resolution of the observed activations. Nonetheless, we ensured that coverage included regions relevant for the task. Furthermore, as the same slice location was used for all subjects (see Materials and Methods) any differences (or lack thereof) observed between sessions or groups could not be attributed by differences in signal strength or coverage.

\section{CONCLUSION}

These preliminary results tentatively suggest that REM-D interferes with the brain's capacity to reestablish the adequate excitability necessary for coping with emotional events that may occur during the following day. REM-D effects on emotional reactivity deserve further research, given the chronic sleep restriction so common in modern society that prominently impacts on the amount of REM sleep, as well as for better understanding the role of REM sleep in mood disorders, such as depression and post-traumatic stress disorder, in which repetition of dream content has been interpreted as the need to reprocess an unassimilated material or to the reactivation of a high excitable circuit by REM sleep endogenous activation.

In order to confirm and generalize the findings obtained here, it would be important for future research to examine whether REM-D also affects emotional reactivity in women and to auditory stimuli and whether differences would be observed, in this case, in the auditory cortex, as was the case with visual areas in the present study. In addition, it would be interesting to assess the effects of REM-D on other aspects of emotional processing and social functioning.

In conclusion, the present findings represent, to the best of our knowledge, the first direct evidence for enhanced emotional reactivity to threatening stimuli after REM-D in humans, and for a role, specific for REM sleep, in modulating the neural substrates for emotional responsiveness.

\section{ACKNOWLEDGMENTS}

This work was supported by CONACYT, Project: 50709. RosalesLagarde A. received a grant from CONACYT for graduate studies and post-doc (86800). This work constitutes part of an academic thesis of the Psychology PhD program at UNAM. We thank Julián A. Sánchez Cortázar of Aceleración Nuclear y Resonancia Magnética S. A. de C. V. at Hospital Angeles del Pedregal for fMRI facilities.

for learning. Cogn. Brain Res. 25, 607-623.

Buzsáki, G. (1989). Two-stage model of memory trace formation: a role for "noisy" brain states. Neuroscience 31, 551-570.

Chein, J. M., and Schneider, W. (2005). Neuroimaging studies of practice-related change: fMRI and meta-analytic evidence of domain-general control network
Chuah, L. Y. M., and Chee, M. W. L. (2008). Functional neuroimaging of sleep deprived healthy volunteers and persons with sleep disorders: a brief review. Ann. Acad. Med. Singapore 37, 689-694.

Corsi-Cabrera, M. (1983). Psicofisiología del Sueño. México City: Trillas.
Corsi-Cabrera, M., Lorenzo, I., Arce, C., Ramos, J., and Guevara, M. A. (1996). Time course of reaction time and EEG while performing a vigilance task during sleep deprivation. Sleep 19, 563-569.

Corsi-Cabrera, M., Miró, E., delRío-Portilla, Y., Pérez-Garci, E., Villanueva, Y., and Guevara, M. A. (2003). Rapid eye movement sleep dreaming is characterized 
by uncoupled EEG activity between frontal and perceptual cortical regions. Brain Cogn. 51, 337-345.

Das, G., and Mallick, B. N. (2008). Noradrenaline acting on alphaladrenoceptor mediates REM sleep deprivation-induced increased membrane potential in rat brain synaptosomes. Neurochem. Int. 52, 734-740.

Datta, S. (1997). Cellular basis of pontin ponto-geniculo-occipital wave generation and modulation. Cell. Mol. Neurobiol. 17, 341-365.

Dement, W. C., and Fisher, C. (1963). Experimental interference with the sleep cycle. J. Can. Psychiatr. 8, 400.

Dewson, J. H., Dement, W. C., Wagener, T. E., and Nobel, K. (1967). Rapid eye movement sleep deprivation: a central-neural change during wakefulness. Science 156, 403-406.

Dinges, D. F., Pack, F., Williams, K., Gillen, K. A., Powell, J. W., Ott, G. E., Aptowicz, C., and Pack, A. I. (1997). Cumulative sleepiness, mood disturbance, and psychomotor vigilance performance decrements during a week of sleep restricted to 4-5 hours per night. Sleep 20, 267-277.

Drummond, S. P., Paulus, M. P., and Tapert, S. F. (2006). Effects of two nights sleep deprivation and two nights recovery sleep on response inhibition. J. Sleep Res. 15, 261-265.

Endo, T., Roth, C., Landolt, $\mathrm{H}$. P., Werth, E., Aeschbach, D., Achermann, P., and Borbély, A. A. (1998). Selective REM sleep deprivation in humans: effects on sleep and sleep EEG. Am. J. Physiol. 274, R1188-R1194.

Evans, A. C., Camber, M., Collins, D. L., and Macdonald, D. (1994). "An MRI-based probabilistic atlas of neuroanatomy," in Magnetic Resonance Scanning and Epilepsy, eds S. Shorvon, D. Fish, F. Anderman, G. M. Bydder, and H. Stefan (New York, NY: Plenum), 263-274.

Fischer, S., Nitschke, M. F., Melchert, U. H., Erdmann, C., and Born, J. (2005). Motor memory consolidation in sleep shapes more effective neuronal representations. J. Neurosci. 25, 11248-11255.

Franzen, P. L., Siegle, G. J., and Buysse, D. J. (2008). Relationship between affect, vigilance, and sleepiness following sleep deprivation. J. Sleep Res. 17, 34-41.

Greenberg, R., Pillard, R., and Pearlman, C. (1972). The effect of dream (stage REM) deprivation on adaptation to stress. Psychosom. Med. 34, 257-262.

Gujar, N., McDonald, S. A., Nishida, M., and Walker, M. P. (2011). A role for REM sleep in recalibrating the sensitivity of the human brain to specific emotions. Cereb. Cortex 21, 115-123.

Gulyani, S., and Mallick, B. N. (1993). Effect of rapid eye movement sleep deprivation on rat brain Na-K ATPas activity. J. Sleep Res. $2,45-50$.

Hicks, R. R., and Moore, J. D. (1979). REM sleep deprivation diminishes fear in rats. Physiol. Behav. 22, 689-692.

Hong, C. C. H., Gillin, C. J., Dow, B. M., Wu, J., and Buchsbaum, M. S. (1995). Localized and lateralized cerebral glucose metabolism associated with eye movements during REM sleep and wakefulness: a positron emission tomography (PET) study. Sleep 18, 570-580.

Horne, J. J. (2000). REM sleep by default? Neurosci. Behav. Rev. 24, 777-797.

Hu, P., Stylos-Allen, M., and Walker, M. P. (2006). Sleep facilitates consolidation of emotionally arousing declarative memory. Psychol. Sci. 17, 891-898.

Huck, N., McBride, S. A., Kendall, A. P., Grugle, N. L., and Killgore, W. D. S. (2008). The effects of modafinil, caffeine, and dextroamphetamine on judgements of simple versus complex emotional expressions following sleep deprivation. Int. J. Neurosci. 118, 487-502.

Ioannides, A., Corsi-Cabrera, M., Fenwick, P., del-Río-Portilla, Y., Laskaris, N., Khurshudyan, A., Theofilu, D., Shibata, T., Uchida, S., and Kostopoulus, G. (2004). MEG tomography of human cortex and brainstem activity in waking and REM sleep saccades. Cereb. Cortex $14,56-72$.

Kahn-Green, E. T., Lipizzi, E. L., Conrad, A. K., Kamimori, G. H., and Killgore, W. D. S. (2006). Sleep deprivation adversely affects interpersonal responses to frustration. Pers. Individ. Dif. 41, 1433-1443.

Killgore, W. D. S., Balkin, T. J., and Wesensten, N. J. (2006). Impaired decision-making following 49 hours of sleep deprivation. J. Sleep Res. 5, $7-13$.

Killgore, W. D. S., Kahn-Green, E. T., Lipizzi, E. L., Newman, R. A., Kamimori, G. H., and Balkin, T. J. (2008). Sleep deprivation reduces perceived emotional intelligence and constructive thinking skills. Sleep Med. 9, 517-526.

Killgore, W. D. S., Killgore, D. B., Day, L. M., Li, C., Kamimori, G. H., and Balkin, T. J. (2007). The effects of 53 hours of sleep deprivation on moral judgment. Sleep 30, 345-352.

Lang, P. J., Bradley, M. M., and Cuthbert, B. N. (2005). International Affective Picture System (IAPS): Affective Ratings of Pictures and Instruction Manual. Technical Report A-6. Gainesville, FL: University of Florida

Lara-Carrasco, J. L., Nielsen, T. A., Solomonova, E., Levrier, K., and Popova, A. (2009). Overnight emotional adaptation to negative stimuli is altered by REM sleep deprivation and is correlated with intervening dream emotions. $J$. Sleep Res. 18, 178-187.

Lim, A. S., Lozano, A. M., Moro, E., Hamani, C., Hutchison, W. D., Dostrovsky, J. O., Lang, A. E., Wennberg, R. A., and Murray, B. J. (2007). Characterization of REM-sleep associated pontogeniculo-occipital waves in the human pons. Sleep 30, 823-827.

Mallick, B. N., Fahringer, H. M., Wu, M. F., and Siegel, J. M. (1991). REM sleep deprivation reduces auditory evoked inhibition of dorsolateral pontine neurons. Brain Res. 552, 333-337.

Maquet, P., Péters, J. M., Aerts, J., Delfiore, G., Degueldre, Ch., Luxen, A., and Franck, G. (1996). Functional neuroanatomy of human rapid-eye-movement sleep and dreaming. Nature 383, 163-166.

Martínez-González, D., Obermeyer, W., Fahy, J. L., Riboh, M., Kalin, N. H., and Benca, R. M. (2004). REM sleep deprivation induces changes in coping responses that are not reversed by amphetamine. Sleep 21 , 609-671.

McKenna, B. S., Dickinson, D. L., Orff, H. J., and Drummond, S. P. A. (2007). The effects of one night of sleep deprivation on knownrisk and ambiguous-risk decisions. J. Sleep Res. 16, 245-252.

Mitchell, D. G. (2011). The nexus between decision making and emotion regulation; a review of convergent neurocognitive substrates. Behav. Brain Res. 217, 215-231.

Morden, B., Conner, R., Mitchell, G., Dement, W., and Levine, S. (1968). Effects of rapid eye movement (REM) sleep deprivation on shockinduced fighting. Physiol. Behav. 3 , 425-432.
Nishida, M., Pearsall, J., Buckner, R. L., and Walker, P. (2009). REM sleep prefrontal theta and the consolidation of memory. Cereb. Cortex 19, 1158-1166.

Payne, J. D., Stickgold, R., Swanberg, K., and Kensinger, E. A. (2008). Sleep preferentially enhances memory for emotional components of scenes. Psychol. Sci. 19, 781-788.

Peigneux, P., Laureys, S., Fuchs, S., Delbeuck, X., Degueldre, C., Aerts, J., Del Fiore, G., Petiau, C., Luxen, A., van der Linden, M., Cleeremans, A., Smith, C., and Maquet, P. (2001). Generation of rapid eye movements during paradoxical sleep in humans. Neuroimage 14, 701-708.

Rauchs, G., Desgranges, B., Foret, J., and Eustache, F. (2005). The relationship between memory systems and sleep stages. J. Sleep Res. 14, 123-140.

Rechtschaffen, A., and Kales, A. (1968). Eds A manual of standardized terminology, techniques and scoring system for sleep stages of human subjects. Brain Information Service, Brain Research Institute, Los Angeles, CA: University of California.

Rosales-Lagarde, A., del Río-Portilla, Y., Guevara, M. A., and CorsiCabrera, M. (2009). Sudden drop of muscle tone at the onset of REM sleep in humans. Salud Ment. 31, 117-123.

Sterpenich, V., Albouy, G., Boly, M., Vandewalle, G., Darsaud, A., Balteau, E., Dang-Vu, T. T., D'Argembeau, A. D., Gais, S., Rauchs, G., Schabus, M., Degueldre, Ch., Luxen, A., Collette, F., and Maquet, P. (2007). Sleep-related hippocampo-cortical interplay during emotional memory recollection. PLoS Biol. 5:e282. doi: 10.1371/ journal.pbio.0050282

Stevens, J. S., and Hamann, S. (2012). Sex differences in brain activation to emotional stimuli: a metaanalysisi of neuroimaging studies. Neuropsychologia 50, 1578-1593.

Tononi, G., and Cirelli, C. (2003). Sleep and synaptic homeostasis: a hypothesis. Brain Res. Bull. 62, 143-150.

Venkatraman, V., Chuah, Y. M. L., Huettel, S. A., and Chee, M. W. L. (2007). Sleep deprivation elevates expectation of gains and attenuates responses to losses following risky decisions. Sleep 30, 603-609.

Vuilleumier, P., Armony, J. L., Driver, J., and Dolan, R. J. (2001). Effects of attention and emotion on face processing in the human brain: an 
event-related fMRI study. Neuron $30,829-841$.

Wagner, U., Fischer, S., and Born, J. (2002). Changes in emotional responses to aversive pictures across periods rich in slow-wave sleep versus rapid eye movement sleep. Psychosom. Med. 64, 627-634.

Wagner, U., Gais, S., and Born, J. (2001). Emotional memory formation is enhanced across sleep intervals with high amount of rapid eye movement sleep. Learn. Mem. 8, 112-119.

Walker, M. P., and Stickgold, R. (2006). Sleep, memory and plasticity. Annu. Rev. Psychol. 57, 139-166.
Walker, M. P. (2009). The role of sleep in cognition and emotion. Ann. N.Y. Acad. Sci. 1156, 168-197.

Walker, M. P., and van der Helm, E. (2009). Overnight therapy? The role of sleep in emotional brain processing. Psychol. Bull. 135, 731-748.

Yoo, S., Gujar, N., Hu, P., Jolesz, F. A., and Walker, M. (2007). The human emotional brain without sleepa prefrontal amygdala disconnect. Curr. Biol. 17, R877-R878.

Zohar, D., Tzischinsky, O., Epstein, R., and Lavie, P. (2005). The effects of sleep loss on medical residents' emotional reactions to work events: a cognitive-energy model. Sleep 28, 47-54.

Conflict of Interest Statement: The authors declare that the research was conducted in the absence of any commercial or financial relationships that could be construed as a potential conflict of interest.

Received: 06 February 2012; accepted: 24 May 2012; published online: 18 June 2012.

Citation: Rosales-Lagarde A, Armony JL, del Río-Portilla Y, Trejo-Martínez
$D$, Conde $R$ and Corsi-Cabrera $M$ (2012) Enhanced emotional reactivity after selective REM sleep deprivation in humans: an fMRI study. Front. Behav. Neurosci. 6:25. doi: 10.3389/ fnbeh.2012.00025

Copyright (c) 2012 Rosales-Lagarde, Armony, del Río-Portilla, TrejoMartínez, Conde and Corsi-Cabrera. This is an open-access article distributed under the terms of the Creative Commons Attribution Non Commercial License, which permits non-commercial use, distribution, and reproduction in other forums, provided the original authors and source are credited. 